www.jmscr.igmpublication.org

Impact Factor (SJIF): 6.379

Index Copernicus Value: 79.54

ISSN (e)-2347-176x ISSN (p) 2455-0450

crossrefDOI: https://dx.doi.org/10.18535/jmscr/v6i12.113

Journal Of Medical Science And Clinical Research

IGM Publication

An Official Publication of IGM Publication

\title{
Comparison of Digital X-Ray and USG Detected bone Erosion in Newly Diagnosed Rheumatoid arthritis Patients (less than 2 years) Attending a Tertiary Care Hospital in Kolkata
}

\author{
Authors \\ Pallav Biswas ${ }^{1}$, Raja Bhattacharya ${ }^{2^{*}}$, Ritasman Baisya ${ }^{3}$, Urmimala Bhattacharjee ${ }^{4}$, \\ Akashdisp Bhattacharya ${ }^{5}$, Tapabrata Das ${ }^{6}$ \\ ${ }^{1}$ Senior Resident, ${ }^{2}$ Assistant Professor, ${ }^{3,4,5,6}$ Juniour Resident, Dept. of Medicine, \\ Medical College and, Hospital, Kolkata, India \\ *Corresponding Author \\ Dr Raja Bhattacharya \\ Email: rbrbhattacharya@gmail.com
}

\begin{abstract}
Introduction: Rheumatoid arthritis (RA) is a chronic inflammatory disease of marked by a symmetric, peripheral polyarthritis. Bone erosion is an integral part of RA, our aim of this study is to find out that among digital radiography and ultrasosnography, which investigation picks up bone erosion more easily and earlier, thus picking up deformity earlier.

Methodology: It was cross-sectional study, conducted in the Rheumatology OPD of Medical College, Kolkata during a period of 1 year among 77 adult literate person. Digital radiography and ultrasonography of peripheral joints were done, and comparison was done to find out which modality detected the joint deformity earlier.

Results: In our study population usg was a better modality of imaging than digital radiography for detecting joint deformity in newly diagnosed RA patoent.
\end{abstract}

\section{Introduction}

Rheumatoid arthritis is a chronic multisystem of unknown aetiology. The characteristic feature of rheumatoid arthritis is persistent inflammatory synovitis. The potential of synovial inflammation to cause cartilage damage and bone erosion and subsequent changes in joint integrity is the hallmark of the disease ${ }^{1}$.

The natural history of the disease is such that the early months of the disease is critical period during which joint damage occurs. So, if a patient presents with 3 or more swollen joints, with metacarpophalangeal, metatarsophalangeal joint involvement and morning stiffness, it is necessary to assess the condition.

Early diagnosis of rheumatoid arthritis and early disease modifying antirheumatoid drugs (DMARDs) application is the only way to save the patient from crippling disease. Study by Ideguchi, et al, ${ }^{[2]}$ reported that not only could the disease be halted with therapy, bone erosions in rheumatoid arthritis could even be repaired by reduction in disease activity. This could be achieved even with the help of conventional disease modifying anti-rheumatic drugs. 
The recommendation now is to treat the disease to remission, which is the target. Remission is said to have been achieved if the disease activity is lowered below a certain score. However, clinical remission may not always translate into radiological halting of erosion, as has been shown by Molenaar, et $\mathrm{al},{ }^{[3]}$. Thus, there is need for investigations which can detect and even quantify the disease for better assessment of the disease.

In a developing country like India, the cost of investigation is a significant factor for most of the patients. From the doctor's point of view, it is also necessary to try to limit the radiation exposure to the patients. Ultrasonography has the advantage of being economic inspite of its sensitivity in assessing both inflammatory and destructive changes.

Ultrasonography has now gained prominence in rheumatology as it can not only be used to diagnose bone erosion, it can simultaneously be used to see ligament, muscle, peripheral nerve and cartilage pathology readily ${ }^{\text {[4] }}$

Bone erosions can be defined as intra-articular discontinuity of the bone surface that is visible in two perpendicular planes ${ }^{[5]}$.

Rheumatoid arthritis is a chronic systemic inflammatory disorder that may affect many tissue and organs but principally attack synovial joints. The process involves inflammatory response of the capsule around the joints, secondary hyperplasia of synovial cells, excess synovial fluid formation and development of pannus in the synovium. Pathology of the disease process often leads to destruction of the articular cartilage and ankylosis of the joint. Rheumatoid arthritis can also cause inflammation in pleura, pericardium and sclera. It can also result in nodular lesion in subcutaneous tissue.

Although the cause of rheumatoid arthritis is not known, autoimmunity plays a vital role in both its chronicity and progression. Thus, rheumatoid arthritis is

now considered a systemic autoimmune disease. This can explain that bone erosion, which is a hallmark of rheumatoid arthritis, not only predicts morbidity; it is also associated increased mortality $[6,7,8]$

About $1 \%$ of the world's population is afflicted by rheumatoid arthritis. Women are affected 3 times more commonly than the males. Onset is most frequently between ages 40 and 50 years, but people from any age group can be affected.

In addition, individuals with HLA-DR1 and HLADR4 serotypes have an increased risk for developing the disorder. It can be disabling and painful condition which can lead to substantial loss of function and mobility if not adequately treated. It is a clinical diagnosis made on the basis of symptoms, physical examination, radiography and laboratory tests. Patients are classified as rheumatoid arthritis if they fulfil the ACR/EULAR criteria for classification.

\section{Materials and Methods}

Study area: Rheumatology and medicine out patients department (OPD) of Medical College and Hospital, Kolkata.

Study Population: all patients with newly diagnosed rheumatoid arthritis (less than 2yrs), satisfying inclusion and exclusion criteria and giving informed consent

Study period: January 2016- June 2017

Definition of Problem: Rheumatoid arthritis (RA) is the most common chronic inflammatory arthritis, affecting $0.5 \%$ to $1 \%$ of the general population worldwide. There is evidence that the overall incidence of RA has been decreasing in recent decades, whereas the prevalence has remained the same because individuals with RA are living longer. Like many other autoimmune diseases, RA occurs more commonly in females than in males, with a 2-3:1 ratio. Pain in joints gradually progressing into joint deformity and disability are important clinical feature of the disease. Diagnosis is made on the basis of clinical feature of chronic arthritis of $>6$ weeks involving usually more than one small and/or large joint. Laboratory and radiological data provide additional aid to diagnosis. The 2010 ACR EULAR revised -Classification Criteriall yields a 
score of $0-10$. Scores $\geq 6$ fulfil the requirement of definite RA diagnosis [51].

Bone erosion is the most characteristic lesion of the disease, which graduallyleads to deformity, adding to morbidity associated with the disease.

Sample size

A total of 77 patients were studied

Study variables

All patients were studied on the basis of following variables-

1) Demographic evaluation

2) Clinical evaluation

3) Digital radiography of hands and feet

4) Ultrasonography of hands and feet

5) Estimation of CBC, ESR and CRP

\section{Inclusion criteria}

1. Age more than 15 years

2. Rheumatoid arthritis diagnosed by fulfilling 2010 ACR/EULAR criteria(11)

3. Disease duration less than 2 years

\section{Exclusion criteria}

1) Patients with chronic renal failure

2) Patients with multiple myeloma

3) Pregnant patients

4) Patients with diabetes mellitus

5) Critically ill patients

6) Unwilling patients

7) Patients with other arthritis (e.g. reactive, gouty, traumatic)

\section{Study design}

Hospital based cross-sectional comparative study

Method of data collection

Following entry into study, demographic data of the patients were collected. A thorough history was taken regarding inflammatory arthritis, duration of the disease, drugs taken; adherence to treatment, presence of other diseases was taken. Then digital radiography was done of both hands and both feet.

Ultrasonography of joints was done. The CBC, ESR and CRP values were checked and RF and anti-CCP values were noted. The patients were then grouped according to disease activity and the erosion were observed in $\mathrm{x}$-ray and USG and compared. For a subgroup of patients, the $\mathrm{x}$-ray and USG evaluation were repeated by a second person, and agreement or disagreement between two persons were also noted

Parameters to be studied

1. Clinical assessment including tender, swollen joint count and pattern of joint involvement

2. Determination of disease activity score

3. Radiographic examination of metacarpophalangeal joints excluding the first joint, proximal inter phalangeal joints of the hand, metatarsophalangeal joint, excluding the first joint

4. Ultrasonography of same joints.

\section{Study Tools}

1. Thorough history taking and clinical examination

2. Digital x-ray of hands(PA view) and feet( AP view) using PHILLIPS ALLURA XPER FD 20 machine

3. USG of hands and feet using PHILLIPS ClearVue 850 machine with linear transducer (5-17 MHz)

4. ESR estimation using Westergreen tube

5. CRP estimation using Erba Mannheim CHEM-5 Plus V2 semiautoanalyser using BioSystems reagent

6. CBC analysis using SysMex autoanalyser

7. Rheumatoid Factor estimation

8. Anti-CCP estimation

\section{Results and Analysis}

Sex

There were 63 females and 14 male patients with sex ratio $\mathrm{M}: \mathrm{F}=1: 4.5$

(Table 1, figure 1)

Table 1: Distribution of the study population according to sex $(n=77)$

\begin{tabular}{|l|c|c|}
\hline Sex & Frequency & Percentage \\
Female & 63 & 81.8 \\
\hline Male & 14 & 18.2 \\
\hline Total & 77 & 100 \\
\hline
\end{tabular}

\section{Age Distribution}

Distribution of study population according to sex 
Table 2: Distribution of study population according to sex $(n=77)$.

\begin{tabular}{|l|c|}
\hline Age category & Frequency \\
\hline $0-10$ & 0 \\
\hline $11-20$ & 0 \\
\hline $20-30$ & 0 \\
\hline $31-40$ & 6 \\
\hline $41-50$ & 17 \\
\hline $51-60$ & 38 \\
\hline $60-70$ & 16 \\
\hline
\end{tabular}

Conclusion: Most of the study population were between 51-60

\section{Erosions in Right MCP Joints by USG}

Number of erosions noted in right sided MCP joint

Table 3: Distribution of study population according to 1st Observers opinion on USG findings of Right sided Meta Carpo Phalangeal Joint $(\mathrm{n}=77)$

\begin{tabular}{|l|c|c|}
\hline Number of erosions & frequency & percent \\
\hline 0 & 53 & 68.8 \\
1 & 20 & 26.0 \\
2 & 4 & 5.2 \\
\hline Total & 77 & 100 \\
\hline
\end{tabular}

Conclusion (1)No erosion could be detected in most of the study population( $68.8 \%)$

(2) On 4 occassions, more than 1 erosion could be detected in themcp joint.

\section{Erosions in Right PIP Joint by USG}

Number of erosions noted in right sided PIP joint by USG

Table 11: Distribution of study population according to 1st Observers opinion on USG findings of Right sided proximal interphalangeal joint $(\mathrm{n}=77)$

\begin{tabular}{|l|c|c|}
\hline Number of erosions & frequency & percent \\
\hline 0 & 71 & 92.2 \\
\hline 1 & 6 & 7.8 \\
Total & 77 & 100.0 \\
\hline
\end{tabular}

Conclusion: Bone erosion could be detected in only $6(7.8 \%)$ occasions in right

PIP joints in the study population using USG.

\section{Erosions in Right MTP Joint by USG}

Number of erosions noted in right sided MTP joint
Table 12: Distribution of study population according to 1st Observers opinion on

USG findings of Right sided metatarsophalangeal joint $(n=77)$

\begin{tabular}{|l|c|c|}
\hline Number of erosions & frequency & percent \\
\hline 0 & 62 & 80.5 \\
\hline 1 & 15 & 19.5 \\
Total & 77 & 100.0 \\
\hline
\end{tabular}

Conclusion: Bone erosion could be detected on $15(19.5 \%)$ occasions in right

MTP joints in study population using USG.

\section{Erosion in Left MCP Joint by USG}

Number of erosions noted per MCP joint by 1 st observer

Table 13: Distribution of study population according to 1st Observers opinion on USG findings of left sided metacarpophalangeal joint $(\mathrm{n}=77)$

\begin{tabular}{|l|c|c|}
\hline Number of erosions & frequency & percent \\
\hline 0 & 40 & 51.9 \\
\hline 1 & 29 & 37.7 \\
\hline 2 & 8 & 10.4 \\
\hline Total & 77 & 100.0 \\
\hline
\end{tabular}

Conclusion: (1) Single bone erosion could be detected in 29 (37.7\%) joints in left MCP joints

(2) More than 1 erosions were detected in 8 joints in left MCP joints.

\section{Erosions in Left PIP Joint by USG}

Number of erosions noted in left PIP joint by 1 st observer

Table 14: Distribution of study population according to 1 st Observers opinion on USG findings of left sided proximal interphalangeal joints $(n=77)$

\begin{tabular}{|l|c|c|}
\hline Number of erosions & frequency & percent \\
\hline 0 & 69 & 89.6 \\
1 & 7 & 9.1 \\
2 & 1 & 1.3 \\
\hline Total & 77 & 100 \\
\hline
\end{tabular}

Conclusion: (1) Single erosion was detected in $7(9.1 \%)$ joints among the studypopulation

(2) More than 1 erosion were detected in 1 joint in the study population

\section{Erosions in Left MTP Joint by USG}

Number of erosions detected in left MTP joint by 1 st observer 
Table 15: Distribution of study population according to 1st Observers opinion on USG findings of left sided metatarsophalangeal joints $(n=77)$

\begin{tabular}{|l|c|c|}
\hline Number of erosions & frequency & percent \\
\hline 0 & 58 & 75.3 \\
1 & 18 & 23.4 \\
3 & 1 & 1.3 \\
\hline & 77 & 100.0 \\
\hline
\end{tabular}

Conclusion: (1) Single erosion was detected in $18(23.4 \%)$ joints in the study

population

(2) More than one erosion was detected in only 1 joint in the study population.

\section{Erosions in Right MCP Joint by X-Ray}

Number of erosions detected in right MCP joint by 1 st observer

Table 16: Distribution of study population according to 1 st Observers opinion on X-ray findings of Right sided metacarpophalangeal joints $(\mathrm{n}=77)$

\begin{tabular}{|l|c|c|}
\hline Number of erosions & frequency & percent \\
\hline 0 & 62 & 80.5 \\
\hline 1 & 12 & 15.6 \\
\hline 2 & 3 & 3.9 \\
\hline Total & 77 & 100.0 \\
\hline
\end{tabular}

Conclusion: (1) Single erosion was detected in 12 right MCP joints in the studypopulation

(2) More than 1 bone erosion was detected in 3 right $\mathrm{MCP}$ joints in the study population.

\section{Erosions in Right Pip Joint by X-Ray}

Number of erosions detected in right PIP joint by 1st observer

Table 17: Distribution of study population according to 1st Observers opinion on X-ray findings of Right sided proximal interphalangeal joints $(n=77)$

\begin{tabular}{|l|c|c|}
\hline Number of erosions & frequency & percent \\
\hline 0 & 74 & 96.1 \\
\hline 1 & 3 & 3.9 \\
\hline Total & 77 & 100.0 \\
\hline
\end{tabular}

Conclusion: Single erosion was detected in only 3 right MCP joints in the study Population.

\section{Erosions in Right MTP Joint by X-Ray}

Number of erosions detected in right MTP joint by 1 st observer
Table 18: Distribution of study population according to 1 st Observers opinion on X-ray findings of Right sided metatarsophalangeal joints $(\mathrm{n}=77)$

\begin{tabular}{|l|c|c|}
\hline Number of erosions & frequency & percent \\
\hline 0 & 71 & 92.2 \\
\hline 1 & 6 & 7.8 \\
\hline total & 77 & 100.0 \\
\hline
\end{tabular}

Conclusion: Single erosion was detected in only 6 right MTP joints in the study population.

\section{Erosions in Left MCP Joint by X-Ray}

Number of erosions detected in left MCP joint by 1st observer

Table 19: Distribution of study population according to 1 st Observers opinion on X-ray findings of left sided metacarpophalangeal joints $(\mathrm{n}=77)$

\begin{tabular}{|l|c|c|}
\hline Number of erosions & frequency & percent \\
\hline 0 & 55 & 71.4 \\
\hline 1 & 22 & 28.6 \\
\hline Total & 77 & 100.0 \\
\hline
\end{tabular}

Conclusion: Single erosion was detected in 22 left MCP joints in the study population.

\section{Erosions in Left PIP Joint by X-Ray}

Number of erosions detected in left PIP joint by 1st observer

Table 20: Distribution of study population according to 1 st Observers opinion on X-ray findings of left sided proximal interphalangeal joints $(n=77)$

\begin{tabular}{|l|c|c|}
\hline Number of erosions & frequency & percent \\
\hline 0 & 76 & 98.7 \\
\hline 1 & 1 & 1.3 \\
\hline Total & 77 & 100.0 \\
\hline
\end{tabular}

Conclusion: Only 1 erosion was detected in 1 left PIP joint in the study population.

\section{Erosion in Left MTP Joint by X-Ray}

Number of erosion detected in left MTP joint by 1 st observer 
Table 21: Distribution of study population according to 1 st Observers opinion on X-ray findings of left sided metatarsophalangeal joints $(n=77)$

\begin{tabular}{|l|c|c|}
\hline Number of erosions & frequency & percent \\
\hline 0 & 66 & 85.7 \\
\hline 1 & 11 & 14.3 \\
\hline total & 77 & 100.0 \\
\hline
\end{tabular}

Conclusion: Single erosion could be detected in 11(14.3\%) left MTP joints in the study population

\section{Comparison of Bone Erosion Detected by USG and X-Ray by the 1st Observer}

Table 25: Comparison of the total number of erosions detected by USG and X ray by person 1 $(n=77)$

\begin{tabular}{|l|c|c|}
\hline & Erosion byUSG & Erosion by X Ray \\
\hline Mean & 1.623376623 & 0.779220799 \\
\hline Variance & 2.079972659 & 0.805878332 \\
\hline observations & 77 & 77 \\
\hline df & 127 & \\
\hline tStat & 4.360447306 & \\
\hline P(T<=t)two-tail & 0.0000 & \\
\hline T Critical two-tail & 1.978819508 & \\
\hline
\end{tabular}

Conclusion: (1) Mean number of erosions detected by USG was 1.62

2) Mean number of erosions detected by X-ray was 0.78

(3) USG detects significantly more number of erosions when compared to X-ray $(\mathrm{p}<0.01)$

\section{Discussion}

Regarding the distribution of erosions, the MCP joints of the left hand had maximum number of erosions, followed by MCP joints of the right hand, then MTP joints of the left foot, followed by MTP joints of the right foot. A study by Tamas, et al found that most erosions were detected via USG in the $5^{\text {th }}$ MTP heads followed by 2 nd and 5 th MCP heads. This observation could possibly be because of the ease of patients positioning and the ease of probe positioning.

Most joints had single erosion. however, in right and left 2nd MCP joints 2erosions could be seen on a few occasions. They were seen more using USG than by X-ray.

Among Rheumatoid Factor and anti-CCP, both correlate significantly with bone erosions detected by USG $(\mathrm{p}<0.05$ and $\mathrm{p}<0.01$, respectively). However, anti-CCP correlates more strongly than rheumatoid factor with bone erosions detected by USG (Pearson coefficient $=0.554$ and Pearson coefficient $=0.29$ ).

The relationship between anti-CCP, rheumatoid factor and bone erosions are similar when erosions detected by X-ray is considered. This finding is similar tohe findings reported in the study by Susanna Maddali Bongi, et al, O. Meyer, et al, N. Samanci, et al, Hyun Hee kim, et al, and all of which suggest that that patients who are positive for anti-CCP had more radiographic joint damage on subsequent follow up.

Studies by D. Aleteha, et al and van Steenbergen, et al on the contrary found that rheumatoid factor and not anti-CCP is associated with more erosive disease. They also said that anti-CCP has little or no effect on disease activity.

In our study we find that the bone erosion correlates positively with the disease activity. However, our study was a cross-sectional study. so we do not know whether bone erosion correlates better with persistent disease activity or not.

Salaffi, et al and Naredo, et al suggested in their studies that bone erosion correlated better with persistently high disease activity. Joshua F Baker, et al had similar outcome from his study. he additionally found that these erosions were better detected by MRI. Radiography was a poor choice for detection of such erosions.

Among disease activity indices, SDAI correlates maximally with bone erosions $(\mathrm{p}<0.01$, Pearson coefficient $=0.552$ ) detected by USG, followed by CDAI $\quad(\mathrm{p}<0.01$, Pearson coefficient $=0.549)$, DAS28-ESR $(p<0.01$, Pearson coefficient $=0.526)$, DAS28-CRP ( $\mathrm{p}<0.01$, Pearson coefficient $=0.512$ ). This was likely as SDAI includes all the variables like tender joint count, swollen joint

count, CRP, patient's assessment and physician's assessment, and gives equal weight age to all the variables.

Bone erosions detected by X-ray however correlate more strongly with DAS28- CRP 
$(\mathrm{p}<0.01$, Pearson coefficient $=0.511)$, closely followed by SDAI $(\mathrm{p}<0.01$, Pearson coefficient $=0.509$ ). CDAI ranked third in correlation $(\mathrm{p}<0.01$, Pearson coefficient $=0.504)$ followed by DSA28-ESR $(p<0.01)$ We could detect a total number of 125 erosion by USG(grey scale) and 60 erosions by digital X-ray among our study population of 77. Students's T test was performed which showed that USG detected significantly more number of erosions when compared to $\mathrm{X}$-ray $(\mathrm{p}<0.01)$.

This observation corresponds with the study of R. Wakefield, et al where they detected 6.5 fold more erosions using USG, as compared to X-ray in early rheumatoid arthritis. Robert Lopez Ben, et al, [66] also found that USG could detect erosions which X-ray could not detect.

W. Grassi, et al gave opinion that radiographic detection of small erosion may be delayed due to patient positioning and technical reasons. The multiplanar capabilities of USG allow a careful assessment of bone surfaces on more views than those allowed by standard radiographs. This improves sensitivity of usg in detecting small erosion, especially in areas not seen in standard views. these opinions corroborated perfectly with our experience while conducting the study.

Study by M. Szkudlarek found high inter observer agreement rates for the identification of bone erosions, using ultrasonography of finger and toe joints in RA. Signs of inflammation were more frequently detected with ultrasound than with clinical examination. Ultrasonography may improve the assessment of RA patients by rheumatologists.

\section{Conclusion}

In conclusion, this study demonstrates the following findings:

Firstly, in patients with early rheumatoid arthritis, USG (grey scale) is a better investigation as compared to digital X-ray for detection of bone erosion in the 77 subjects studied in our study.

Secondly, disease activity index SDAI correlates maximally with bone erosions detected by USG and DAS28-CRP correlates maximally with bone erosions detected by X-ray.

Thirdly, anti-CCP correlates better with bone erosion detection than Rheumatoid Factor, though association of both are significant.

Lastly, USG has much better inter-observer agreement than X-ray. Thus USG is a better standardised test than X-ray and may have better reproducibility

\section{Limitation}

The limitations of my study are-

1) This is a cross-sectional study. single determination of inflammatory marker and disease activity may not always accurately represent course and burden of the disease

2) Sample size was small. A larger sample size would have increased the power of the study.

3) This was a female predominant study with less male attendance

4) Relative subjective feeling of the patients may affect scoring

5) A good number of patients are treated at the orthopaedics Out patients department

6) This was a single centre study. A multicentre study involving more number of rheumatologists would have been more desirable.

\section{Reference}

1. Shah A, Claire W. Rheumatoid arthritis. Chapter 380. In: Kasper DL, Fauci AS, Hauser SL, et al, eds. Harrison's principle of internal medicine. 19th edn. 2015:21372148

2. Ideguchi H, Ohno S, Hattori H, Senuma A, Ishigatsubo Y 2006 Bone erosions in rheumatoid arthritis can be repaired through reduction in disease activity with conventional disease-modifying antirheumatic drugs. Arthritis Res Ther 8: R76

3. Molenaar ET, Voskuyl AE, Dinant HJ, Bezemer PD, Boers M, Dijkmans BA. Progression of radiologic damage in 
patients with rheumatoid arthritis in clinical remission. Arthritis Rheum 2004; 50: 36-42.

4. Kane D, Grassi W, Sturrock R. Musculoskeletal ultrasound-a state of the art review in rheumatology. Part 2: Clinical indications for musculoskeletal ultrasound in rheumatology. Rheumatology (Oxford) 2004;43:829-838

5. Wakefield RJ, Balint PV, Szkudlarek M, Filippucci E, Backhaus M, D'Agostino MA, et al, OMERACT 7 Special Interest Group. Musculoskeletal ultrasound including definitions for ultrasonographic pathology. J Rheumatol 2005; 32: 2485-7.

6. Ødegård $\mathrm{S}$, et al. Association of early radiographic damage with impaired physical function in rheumatoid arthritis: a ten-year, longitudinal observational study in 238 patients. Arthritis Rheum. 2006;54:68-75.

7. Scott DL, et al. The links between joint damage and disability in rheumatoid arthritis. Rheumatology (Oxford) 2000;39:122-132.

8. Welsing PM, van Gestel AM, Swinkels HL, Kiemeney LA, van Riel PL. The relationship between disease activity, joint destruction, and functional capacity over the course of rheumatoid arthritis. Arthritis Rheum. 2001;44:2009-2017.

9. Enzer I, Dunn G, Jacobsson L. An epidemiologic study of trends in prevalence of rheumatoid factor seropositivity in Pima Indians. Arthritis Rheum (2002); 46:1729-1734

10. Malaviya AN, Kapoor SK, Singh RR et al. Prevalence of rheumatoid arthritis in the adult Indian population. Rheumatol Int (1993); 13(4): 131-134

11. Chopra A. The COPCORD world of musculoskeletal pain and arthritis. Rheumatology (Oxford) (2013) November; 52(11):1925-1928
12. Mahajan A, Jasrotia DS, Manhas AS, Jamwal SS. Prevalence of major rheumatic disorders in Jammu. JK Science (2003); 5:63-66

13. Hemminki K, Li X, Sundquist J, Sundquist K. Familial associations of rheumatoid arthritis with autoimmune diseases and related conditions. Arthritis Rheum (2009); 60:661-668

14. Rak JM, Maestroni L, Balandraud N, et al. Transfer of the shared epitope through microchimerism in women with rheumatoid arthritis. Arthritis Rheum (2009); 60:73

15. van der Helm-van Mil AH, Verpoort KN, Breedveld FC et al. The HLADRB1 shared epitope alleles are primarily a risk factor for anti-cyclic citrullinated peptide antibodies and are not an independent risk factor for development of rheumatoid arthritis. Arthritis Rheum (2006); 54:1117. 